\title{
La pastoreta, Fèlix, el llop i Bernat Metge: a propòsit de l'episodi inicial del Libre de Meravelles de Ramon Llull
}

\author{
Miquel Marco Artigas
}

El primer llibre del Libre de meravelles s'inicia amb un episodi força curiós. La intencionalitat de l'obra s'expressa en el pròleg: En tristícia e en languiment stava un home en stranya terra. ${ }^{1}$ Fortment se meravellava de les gents de aquest món, com tan poch conexien e amaven Déu, qui aquest món ha creat e donat als hòmens en gran noblea e bonea, per tal que per ells fos molt amat e conegut. Aquest home plorava e planyia com Déus en est món ha tan pochs amadors e servidors e lohadors. E per ço que sia conegut, amat e servit, fa aquest Libre de meravelles lo qual deperteix en $\cdot x \cdot$ parts, ço és a saber: Déu, Àngels, Cel, Elements, Plantes, Metalls, Bèsties, Home, Peradís, Infern. ${ }^{2}$ Per tant, el lector, ja des del primer moment, espera que Llull entri a filosofar sobre Déu. Però no és així, el capítol dedicat a provar l'existència de Déu s'obre amb una pastorel.la. ${ }^{3}$

La pastorel-la és un gènere poètic trobadoresc condicionat pel seu contingut. Aquesta composició és un diàleg entre un cavaller i una noia del camp, de condició social baixa, a la qual intenta seduir. El tractament que es fa de la figura de la noia és força respectuós i moltes vegades ella mostra major enginy que el cavaller a l'hora de resoldre la situació compromesa en què es troba. La pastorel.la sol tenir dos desenllaços: la pastora rebutja el cavaller amb el seu gran enginy o amb l'ajuda familiar que, algunes vegades, es tradueix en una pallissa al cavaller.

El trobador Marcabrú, ja en el segle XII, introdueix una variant on la pastora dóna lliçons de tipus moral-sexual al cavaller. ${ }^{4}$ Guillem de Girona, coetani de

1 Aquesta estranya terra és París, on va escriure l'obra entre 1288 i 1289. Cfr. Ramon Llull, Libre de meravelles, vol I, Barcino, Els Nostres Clàssics, Col-lecció A, n. ${ }^{\circ}$ 24, Barcelona, 1934, pp. 810, edició a cura de Mn. Salvador Galmés.

${ }^{2}$ Ramon Llull, Libre de meravelles, op, cit., pàg. 25. La resta de cites textuals d'aquest treball també estan extretes d'aquesta edició de l'obra de Llull.

${ }^{3}$ Segons Riquer, sense cap mena de preàmbul i sense cap sospita per part del lector la narració comença en un estil típic trobadoresc. A més les pastorel-les profanes tradicionals solen iniciar el diàleg amb la paraula «amiga» i la resposta de la mossa, «Sènyer». Història de la Literatura Catalana, vol. I, Ariel, Barcelona, 1984 (4. $\left.{ }^{\mathrm{a}}\right)$, pàg. 294.

${ }^{4}$ Vid, Anthony Bonner i Lola Badia, Ramon Llull (vida, pensament i obra literària), Les Naus d'Empúries, Pal Major 2, Barcelona, 1991 (2. a), pp. 88-89. En aquesta obra, els autors fan una 
Llull, compon una pastorel-la on el cavaller vol aconseguir favors sexuals de la jove, però ella troba arguments suficients, malgrat les seves promeses, per no accedir als desitjos del cavaller. L'amor forçat no fa profit, aquest és l'ensenyament de la pastora. ${ }^{5}$ Ella sap que la relació amb el cavaller no li és beneficiosa perquè ambdós pertanyen a estaments socials molt diferenciats.

Fèlix, protagonista de l'obra, és enviat pel seu pare a recórrer món i saber els motius pels quals els homes deixen d'estimar i de conèixer Déu. ${ }^{6}$ Un cop s'ha acomiadat del pare $i$ ha iniciat el viatge, es troba en un gran boscatge amb una pastoreta que guarda el seu ramat. Es meravella d'ella en veure-la sola en aquell indret perillós, ple de feres que poden fer-li mal. La pastora li respon que ella està molt segura perquè Déu vetlla per ella:

Com Fèlix fon pertit de son pare, e fo en un gran boscatge, e ach anat longament, sí encontrà una azalta pastoresa qui guardava bestiar, -Amigua - dix Fèlix-, molt me meravell de vós com tota sola stats en est boscatge, en què són moltes males bísties qui porien dar dampnatge a vostra persona; $e$ vós no havets força que vostres ovelles als lops ne a les males bísties deffendre poguéssets.-

Dix la pastoressa: - Sènyer, Deús és sperança, companyia e confort de mon coratge; e en sa guarda e virtut stich en aquest boscatge, car ell ajuda a tots aquells qui en ell se confien; cor ha tot poder e tota saviesa e tota bondat, són-ma mesa en sa guarda e en sa companyia.-

Molt plagueren a Fèlix les paraules que dix la pastora de nostro senyor Déus, e meravellà's com en ella havia tanta de sperança e de saviesa; e anà avant en son viatge (Lb. I, cap. I).

Fèlix marxa feliç del lloc veient una actitud de gran fermesa i seguretat en la pastoreta. Sent una certa atracció honesta per la mossa. ${ }^{7}$ Aquesta admiració està exempta de qualsevol connotació de tipus amorós. És una atracció totalment pura i produïda per la forma d'actuar de la pastora. Ni la solitud del paratge (amb possibles reminiscències de locus amoenus) ${ }^{8}$ on es troben sols els dos joves juga un paper temptador. Llull vol, en aquest primer capítol, presentar-nos el primer

síntesi de les diverses versions de les pastorel-les, així com un estudi sobre els elements que caracteritzen la literatura lul-liana.

5 Ibid, pàg. 88.

${ }^{6}$ El jove Fèlix és caracteritzat com una emanació de l'ànima lul-liana i en sembla un desdoblament. Cfr. Jordi Rubió i Balaguer, «Pròleg al Llibre de les bèsties» a Ramon Llull i el lul-lisme, Publicacions de l'Abadia de Montserrat, Barcelona, 1985, pàg. 316.

${ }^{7}$ Bonner i Badia parlen d'una pastoreta coratjosa i exemplar que captiva amb aquestes virtuts Fèlix però també paren atenció al qualificatiu azalta que li atribueix Llull. Aquest occitanisme molt emprat en la literatura trobadoresca significa 'agradable'. Així, el lector coneixedor d'aquest tipus de gènere sap que les pastoretes són força atractives. Vid, Anthony Bonner i Lola Badia, Ramon Llull..., op. cit., pp. 88-89.

8 A propòsit del locus amoenus, Vid., Jordi Rubió i Balaguer, el «locus amoenus». Com interpreta Ramon Llull el paisatge, a «Alguns aspectes de l'obra literària de Ramon Llull» dins de Ramon Llull i el lul.lisme, op. cit., pp. 284-286. 
dubte de Fèlix, és a dir, la primera temptació i vol que aquesta s'endinsi pels complexos camins de la negació de l'existència de Déu. Fèlix caurà més endavant en una segona temptació, i aquesta sí que tindrà com a base els desigs de posseir una fembra. ${ }^{9}$

Al moment, oeix els seus crits i veu, horroritzat, que un llop ha agafat un dels seus anyells. La pastora surt corrent darrera del llop i aquest deixa la seva pressa i la devora.

Interessant és observar que Llull es val d'aquest episodi de la pastoreta i del llop, amb evidents connotacions de conte (inclús el lector modern - malgrat totes les diferències existents-, no deixa de pensar en el famós conte de la caputxeta vermella i el llop) per expressar el pensament cristià sobre el tema del mal i la justícia divina. És una doctrina inserida en un episodi amb reminiscències de conte popular i així mantenir l'interès absolut del lector perquè el seu alliçonament sigui molt més profitós. Per tant, aquests episodis narratius tenen la funció de captar l'atenció i de moralitzar. No s'ha d'oblidar que Llull escriu sempre amb una finalitat adoctrinadora, Fèlix dialogarà, al final de l'episodi, amb un ermità, obrint-se així una dialèctica de preguntes i respostes i també l'ús de semblances clarificadores. ${ }^{10}$

El desenllaç de l'episodi de la pastoreta deixa Fèlix en un estat de consternació i sofreix la seva primera crisi. La simpatia que sentia per la jove agreuja el sentiment de rebuig cap a un Déu que no ha estat capaç de defensar a qui creia fervorosament en Ell. No s'explica per què Déu no ha salvat aquella noia que li professava tanta fe i confiava cegament en l'Altíssim. Fèlix comença a tenir dubtes sobre l'existència de Déu ja que si aquest existís, amb tota seguretat hauria salvat la pastora. Queda atordit i sobtat davant el mal que reben els bons i la intervenció divina.

${ }^{9}$ Fèlix troba una dona plorosa que li diu que va a veure Blanquerna, sant ermità de gran saviesa a qui la gent acut per cercar consol i consell. Fèlix decideix acompanyar la dona i visitar també Blanquerna. Pel camí, la segona temptació: pecar carnalment amb aquella dona. Fèlix demana ajut a Déu per mitjà d'oracions. Quan veu que la dona també invoca Déu amb devoció i saviesa, la temptació de Fèlix s'esvaeix i finalment arriben a l'ermita de Blanquerna: Dementre que Fèlix anava ab la fembre per lo boscatge, temptació li vench molt gran con peccàs ab la fembre. Molt se meravellà Fèlix de la temptació que hac, e, enfre si mateix, dix a nostre Senyor Déus estes peraules: - Senyor Déus gloriós, qui has tot compliment, ¿com ne per què has desemperat lo teu servidor Fèlix, que tots temps de sa vida proposave en tu conèxer e amar? Ara és Fèlix en peccat e en error, car en la tua santa encarnació és duptós, e en desig de carnal delit és cahut, e.n volentat està com corrompa sa virginitat. [...] Molt se meravellà Fèlix de les paraules de la fembre, cor molt eren peraules devotes e de gran saviesa; e meravellà's con, dient la fembre aytals peraules, podie haver impaciència de la mort de son fill, ne com ell podie haver moviment de luxúria en peccar ab aytal fembre qui tan santes e tan devotes paraules deya de Déu.

Stant Fèlix en est pençament meravellós, ell i la fembra vengueren al hermitatge en lo qual stava lo sant hom Blanquerna (Lb. I, cap. VII).

${ }^{10}$ Cfr. Antony Bonner i Lola Badia, op. cit., pàg. 137. En semblants termes es manifesta Julia Butiñá quan observa que Llull intenta demostrar l'argument de l'existència de Déu mitjançant l'ús de la semblança, més efectiva quan més difícil és. Vid., Julia Butiná, Detrás de los orígenes del Humanismo: Ramon Llull, UNED, Madrid, 2006, pàg. 86. 
Al Llibre de Fortuna e Prudència, de Bernat Metge, aquest, narrador i protagonista del poema arriba a una illa habitada per Fortuna i, dubtós, pronuncia aquestes paraules davant la manca d'explicació sobre el comportament antinatural dels elements que composen aquella illa. ${ }^{11}$

\section{LFP: E tantost fuy d'oppinio que no y era Deu ni natura car no y hac orde ne mesura ne res qui fos fayt per rayso.}

$$
\text { (v.v. 218-221) } 12
$$

Metge desvincula Déu i la natura de tot allò que es pugui apartar de l'Ordre. Així es pot deduir que, si existeix desordre, no existeix Déu.

La manca d'explicació raonable per comprendre l'existència del mal és una de les causes principals d'ateisme. I és en aquest context on es relacionen el Llibre de Fortuna e Prudència i Ramon Llull mitjançant la figura bíblica de Job. ${ }^{13}$

Job és un gentil que es pregunta sobre el bé i el mal i la justícia divina. És un home que busca respostes convincents davant uns fets que no acaba d'entendre i que, fins i tot, es rebel-la quan en la recerca de les respostes que justifiquin la situació en la qual es troba no queda convençut.

El gentil del Libre del gentil e los tres savis és un home que no coneix Déu, no creu en l'existència d'una vida eterna i que es regeix per la raó. La trobada amb els savis farà que un d'ells li demostri que Déu existeix així com també la vida més enllà de la mort terrenal. Ambdues obres són diàlegs sobre els medis humans per comprendre la divinitat.

La figura de Job també hi és present al Libre de Meravelles. La major incidència del llibre sapiencial es troba en el paral-lelisme que ofereixen les dues obres en el mètode de preguntes i respostes mitjançant les quals esvairan els

${ }^{11}$ El Llibre de Fortuna e Prudència és un poema que narra com el dia 1 de maig de 1381, Metge, narrador-protagonista, que es troba en una situació de perill, pateix un accés d'angoixa i decideix sortir de casa a passejar vora el mar. Troba un vell pobre a qui vol socórrer. Aquest no accepta l'almoina de Metge i solament li demana que li atansi un túnica que té dins una barca. Quan puja a la barca, el vell la impulsa mar endins i és així, després d'un viatge on ell no pot governar la barca ja que no té ni rems, ni veles, ni governall, com arriba a l'illa de Fortuna on la natura és contrària a l'ordre establert: els ocells cantaires no canten, els arbres fruiters no donen fruits, el riu sulfurós és qui porta bona aigua, els canvis de temps s'alternen sense cap lògica...

${ }^{12}$ Les cites textuals de l'obra estan extretes de l'edició de Martín de Riquer, Obras de Bernat Metge, Universidad de Barcelona, Barcelona, 1959.

${ }_{13}$ Julia Butiñá, «Una volta per les obres de Metge de la mà de Fortuna e Prudència», a Estudis de Llengua i Literatura Catalanes, XXVI, Miscel-lània Jordi Carbonell, 5, Publicacions de l'Abadia de Montserrat, Barcelona, 1993, pp. 47-70. Vid., també, Detrás de los orígenes..., op. cit., pp.67103. El Llibre de Job és una de les fonts d'influència del Llibre de Fortuna e Prudència. Per les intertextualitats i per la relació entre ambdues obres, Vid. Miquel Marco, «Bernat Metge i Job: dos rebels amb causa però amb resolucions diferents», Revista de Lenguas y Literaturas catalana, gallega y vasca, XI, (2005), pp. 17-27. 
dubtes dels dos protagonistes. Al Llibre de Job són Déu i Job qui estableixen el diàleg i, al Libre de Meravelles són l'ermità i Fèlix.

Job acaba rebutjant els seus amics — són tres savis- que representen la saviesa tradicional que defensa l'existència d'un Déu just i bo, que no castiga els innocents, com a interlocutors i requereix la presència de Déu com a única via de resolució i explicació al seu problema. Vol parlar i discutir amb Déu qui li fa veure la seva incapacitat per comprendre els designis divins. Davant la contundent intervenció de Déu, Job reconeix i accepta tot el que representa la Creació, inclús allò que l'home no pot entendre i que ha d'acceptar.

Fèlix troba un ermità qui li pregunta, en veure'l tan esbalaït, què li ha passat. Ell li explica els fets que han succeit a la pastoreta que el turmenten i l'han fet caure en temptació. Dubta de l'existència de Déu, perquè no ha fet res per ajudar la pastoreta la qual confiava en el Totpoderós, que és poder, saviesa i bondat. Ha permès que el mal afecti els bondadosos: Dementre que Fèlix en aço cogitava e.s meravellava de Déu, qui a la pastora no hac ajudat, pus que en ell se confiava, caech en gran temptació, e dubtà en Déu, e ach opinió que Déu no fos res, car semblant li fo que si Déus fos res, que a la pastora ajudàs (Lb. I, cap. I). L'ermità, primer mitjançant una semblança i després amb un explicació amb la qual justifica l'existència de Déu, convenç Fèlix i aquest acaba lloant Déu perquè l'ha il-luminat amb el seu coneixement.

Metge, a més a més de comprovar la manca d'ordenació racional a l'illa de Fortuna, és enganyat pel vell indigent quan pretenia actuar com a bon cristià. La descreença de Metge no és exclusivament pel desordre natural de l'illa de Fortuna sinó que també es fonamenta en la injustícia de Déu que permet que els bons sofreixin el mal.

LFP: mas Deu, segons qu·avets provat, permet fer molta malvestat.

Donchs, segueix-se qu.Elh es injust

$$
\text { (vv. 771-773) }
$$

Prudència fa veure Metge, i aquest ho reconeix —encara que sota aquest reconeixement s'amaga, de nou, una subtil ironia-, que Déu permet que es faci el mal en el món, i, fins i tot, recolza la seva afirmació en l'aprovació que han fet els sants doctors de l'Església, però malgrat això, a continuació, li assegura que és veritat i és un fonament de raó que Déu no permet que es faci res en el món sense raó.

LFP: car, jatz que Deus moltes errors

e malvestats permeta fer,

e no.s cur soven de reffer

so que sera mal ordonat,

sapgats que pura veritat

es e fundament de raho

que no sofer qu'ab desraho

se fassa res en aquest mon,

(vv. 794-801) 
Arribat aquest punt del diàleg és quan Metge li contesta que ara sí que ja no entén res i la seva resposta demostra que no accepta aquests tipus de raonaments escolàstics que li està plantejant Prudència.

LFP: Are-us dich que pus torbat son,

Senyora, que james no fuy.

[...]

Que.n me fe, quaix heretge·n torn

quan vey que-lls bons sofferen mal,

e los malvats seen egual

dels princeps e dels grans senyors

ez han riqueses ez honors;

e puys que-lls pobles los adoren;

e james no han mal ni ploren

ne saben qu·és adversitat.

(vv. 802-803 i 806-813)

La pastoreta, també, és devorada pel llop al defensar les ovelles, malgrat tenir una gran confiança en Déu.

La consecució d'ambdues actuacions resulta irracional i il-lògica. Les seves actituds, lluny de veure's recompensades, reben com a premi el mal, quedant així palesa la permissibilitat divina enfront el mal i l'existència de la injustícia al món. Davant aquesta situació, ambdós protagonistes dubten de l'existència de Déu: «La reacció de Metge davant el cruel i arbitrari espectacle de l'illa de l'absurd és, doncs, equivalent a la de l'indignat Fèlix en dubte respecte a Déu». ${ }^{14}$

La situació de gran dubte i temptació motivada per les circumstàncies viscudes per Fèlix, li provoquen un estat d'ànim anguniós i preocupant, que tot just li permet articular paraula. Fèlix vaga tot el dia turmentat per la temptació i afermant-se cada cop més que Déu no existeix ja que, si existís, no l'hagués abandonat en temptació quan topa amb l'ermità: Ab aytal temptació e opinió anà tot lo jorn Fèlix tro a la nit, que sdevench en un armitatge en què stava un sant hom qui longament en theologia e en philosophia havia studiat, e, ab sos libres e ab sa saviesa, en aquell armitatge Déu contemplava e adorava. L'ermità saludà Fèlix molt agradablement en son venir, mas Fèlix no li poch res dir, sinó que, tot sbalaït, se gità a sos peus e stech longament ans que perlar pogués; sí que l'ermità se meravellà de Fèlix, que perlar no podia, e en son semblant conexia que alcun sbayment havia. E Fèlix en son coratge se meravellà de la temptació que havia e molt forment lo turmentava; e hon pus fort era temptat, pus fort considerava e afermava que Déus res no fos, car, si fos, ja no.l agera jaquit caure en tan greu temptació (Lb. I, cap. I).

En similar situació de desassossec està Metge quan sap que es troba malalt i —entengui's la paraula des d'una perspectiva moral i no física - demana a Prudència que l'ajudi amb promptitud.

${ }^{14}$ Julia Butiñá, «Una volta per les obres de Metge...», op. cit., pàg. 63. 


\section{LFP: $[\ll \ldots]$}

Sopley-vos, que abans que-s desisqua

l'arma dels cors, me vulhats dir

quin es mon mal, car deffelhir

cuyt, si no m'aydats en breu.»

(vv. 696-699)

I com en totes les situacions plantejades entre les fonts d'influència ${ }^{15} \mathrm{i}$ el Llibre de Fortuna e Prudència, la resolució final del problema de la justícia divina pren camins diferents. Fèlix agraeix les explicacions de l'ermità. Aquest li exposa els principis de la fe cristiana i li respon que el món existeix per ocasió del bé. Sense bé no podria ser el món tan bell com és. Cal l'existència de Déu perquè el món no sigui mal. El bé i l'ésser es relacionen així com el mal i el no-ésser. El món és bo i això prova que Déu existeix. Déu ha volgut que la pastoreta que tant l'estimava, el servia i confiava en Ell gaudís aviat de la glòria $i$ ha fet dubtar Fèlix per fer-lo fort davant les temptacions. L'ermità li explica que sense l'existència de Déu no hi hauria resurrecció i l'home, després de la mort, es convertiria en no-ésser i així seria natural desitjar la mort. Mitjançant aquestes explicacions, l'ermità no solament ha resolt el problema d'ateisme en què ha caigut Fèlix sinó que ha enfortit la fe del jove en Déu després de l'experiència viscuda.

Fèlix ha quedat molt satisfet amb les explicacions de l'ermità: Molt plach a Fèlix la provança que lo hermità hac feta de Déu, e lohà e benesí qui l'avia il-luminat de la sua conexença. Ab contricció e ab plors se rendech a Déu per culpable, e del sant home pres penitència loant Déu (Lb. I, cap. II).

Metge, després del diàleg amb Prudència, qui el considera guarit de la seva malaltia, s'adona que la seva greu situació no ha estat en cap moment resolta i es manté en un pla d'esceptisme en relació a la forma de solucionar aquest problema sobre el mal que afecta els bons i la intervenció de la justícia divina. Aquesta Prudència, que dialoga amb Metge, presenta semblances amb la Filosofia de Boeci a la seva obra De Consolatione Philosophiae. L'exposició

${ }^{15}$ La temàtica que desenvolupa El Llibre de Fortuna e Prudència en el seu contingut —origen del mal i l'actuació divina - es troba present a diversos textos de gran acceptació i arrelament a l'Edat Mitjana. Metge utilitza com a fonts que es relacionen amb el pensament escolàstic, i en concret amb el tema abans esmentat, el Llibre de Job, la filosofia de Sant Agustí, l'obra ortodoxa de Boeci, De Consolatione Philosophiae, i la moral doctrinal de Ramon Llull. Totes aquestes fonts presenten el tema d'un «modus» similar: el dubte i la incomprensió del personatge davant el mal que danya injustament, els bons. La solució que ofereixen aquestes fonts d'influència és la tradicional de l'escolàstica medieval, és a dir, la necessitat de la fe i l'acceptació de la impossibilitat de l'home per a jutjar racionalment la conducta de Déu, per ser matèria que supera el límit del coneixement humà. Metge s'iguala a aquestes fonts ja que necessita resposta a aquests conceptes èticometafísics, i per això també exposa a la seva obra el problema que li cuita. Però ell es desmarca de totes les fonts perquè conclou de forma diferent. La filosofia escolàstica no contribueix a solucionar els dubtes de Metge i, per tant, aquest continua en la mateixa situació d'escepticisme que abans de proposar el debat. Cfr. la introducció a la meva edició crítica del Llibre de Fortuna e Prudència, Reial Acadèmia de Bones Lletres, Series Maior, Barcelona, 2008, en premsa. 
filosòfica de Prudència sobre el mal i la justícia és una síntesi del corpus filosòfic de Boeci. L'exposició emfatitza sobre els conceptes del bé i del mal i l'actitud de la Providència davant la injustícia.

La idea exacta que Boeci vol difondre és que la raó humana està sotmesa com a cosa legítima a la ment divina. Per tant, no pot entendre els grans judicis divins. Metge, com sempre, no queda convençut amb les proposicions tradicionals que li raona Prudència i acaba el seu diàleg amb una actitud escèptica que demostra, de nou, la seva manca de confiança en la filosofia escolàstica per resoldre's el tema tractat.

Prudència considera, després de la seva exposició, que Metge ja està restablert de la seva malaltia, i s'acomiada al-legant tenir pressa. Atònit, el protagonista escolta aquestes darreres paraules de Prudència com si l'hagueren donat un mal cop al cap (ja que encara no ha resolt la seva greu situació) i que paral-lelament, confirmen l'escepticisme absolut del protagonista:

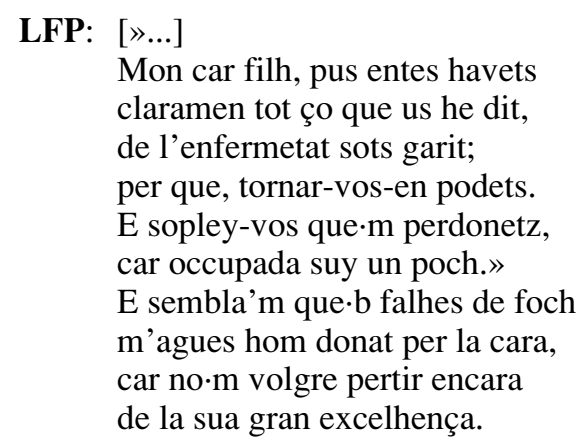

(vv. 1142-1151)

Metge reflexiona sobre els conceptes de la justícia divina i els conceptes del bé i del mal dins d'uns plantejaments molt més moderns dels que la filosofia tradicional li ofereix i això gràcies a l'ús diferent que fa de les fonts d'influència. Així transmet unes idees de racionalisme i escepticisme davant aquests problemes que el preocupen. Són qüestions que l'escolàstica resol de manera que no satisfan el nostre autor: «En funció d'això [menyspreu de l'escolàstica estèril] crec que s'ha de reconèixer al Llibre de Fortuna e Prudència tot el concepte modern de revolta dels criteris establerts a l'antiga usança [...] bo i sospesant bé la possible ombra de Llull». ${ }^{16}$

${ }^{16}$ Com a síntesi del significat de l'obra de Metge i la seva relació amb Llull, trobo molt adient aquesta cita de la doctora Butiñá, Vid., Julia Butiñá «Una volta per les obres de Metge...»op., cit., pàg. 70 . 